\title{
PREDICTIVE VALUE OF EEG FOR NEURODEVELOPMENTAL OUTCOME IN NEONATAL SEIZURES
}

Yogendra S. Verma ${ }^{1}$, Rajdhar Dutt ${ }^{2}$, Neelam Rajput ${ }^{3}$, Rajesh Patil ${ }^{4}$

\section{HOW TO CITE THIS ARTICLE:}

Yogendra S. Verma, Rajdhar Dutt, Neelam Rajput, Rajesh Patil. "Predictive value of EEG for neurodevelopmental outcome in neonatal seizures". Journal of Evolution of Medical and Dental Sciences 2013; Vol2, Issue 29, July 22; Page: 5417-5425.

ABSTRACT: BACKGROUND: This study was conducted in Department of Pediatrics, Kamla Raja Hospital, G.R Medical College, Gwalior (MP). SETTINGS AND DESIGN: It was a Prospective observational type of study. AIMS: This study was done to know the predictive value of EEG for neurodevelopmental outcome in neonatal seizures and to study the prognostic significance of neonatal EEG patterns. METHOD AND MATERIAL: A total of sixty neonates admitted in neonatal unit of this hospital having seizure episode any time after birth were included in this study. Required information of the enrolled cases was recorded in a preformed proforma. The day of onset of seizures, clinical type of seizures were recorded. Electroencephalography (inter ictal) was done in the Department of Neurology Gajra Raja Medical College Gwalior. First EEG was done during the course of stay in the SCNU and the pattern was recorded. Second EEG was done at the age of 3 months and the pattern was recorded in the proforma. EEG patterns were divided into three groups. Neurodevelopment assessment of these babies was done at the age of 6 months using 'C Amiel Tison neurodevelopmental assessment tool'. STATISTICAL ANALYSIS USED: All the data were collected and then processed and analysed. Epical 2000 info software was used for calculation of $\chi^{2}$ value, and P value. Fishers exact test for Risk ratio, Odds ratio were applied using 2 X 2 table. Kappa values were calculated for significance of association. RESULTS AND CONCLUSION: Total 60 cases were enrolled out of them seven cases were lost to follow up during the study. One case died at the age of six months. Only 52 (86.66\%) cases completed the follow -up for neurodevelopmental assessment. Out of sixty 31cases (51.67\%) had seizures within 24 hours of life ( $\mathrm{p}<0.01), 15$ cases $(25 \%)$ had seizures between 24-72 hours of life and 14 cases thereafter. Clonic seizures were found to be the most common type of seizures $40 \%$ ) followed by subtle $31.67 \%$, tonic $20 \%$, and myoclonic $3.33 \%$ seizures. Birth asphyxia $42(70 \%$ ) was the most common etiology of seizures observed in the study followed by hypocalcemia and hypoglycemia and CNS infection 6(10\%). On follow up out of 52 cases, 12 (23.07\%) developed epilepsy. Developmental assessment of the cases shows that $30(57.70 \%)$ were normal, 14 $(26.92 \%)$ were having moderate developmental delay and $8(15.38 \%)$ were having severe neurodevelopmental delay. In $1^{\text {st }} \mathrm{EEG}$, group I pattern had $87.5 \%$ normal outcome, group II pattern had $47.4 \%$ moderate delay and group III pattern had $66.7 \%$ severe delay. In $2^{\text {nd }}$ EEG, group I pattern had $90.3 \%$ normal outcome, group II pattern had $69.24 \%$ moderate delay and group III pattern had $75 \%$ severe delay. In normal pattern $1^{\text {st }}$ EEG $87.5 \%$ cases were having normal outcome while in normal pattern $2^{\text {nd }}$ EEG $90.3 \%$ were with normal outcome. In abnormal $1^{\text {st }}$ EEG 68\% cases were having developmental delay while in abnormal $2^{\text {nd }}$ EEG $90.5 \%$ cases were found to be having developmental delay.

KEYWORDS: Birth asphyxia; EEG; Neonate; Neurodevelopment; Seizures.

INTRODUCTION: The occurrence of seizure may be the first and perhaps the only clinical sign of a central nervous system disorder in newborns. The occurrence of seizure in neonates may be due to very wide range of etiologies like asphyxia, metabolic disturbances, infection or IVH etc. 
King Edward Memorial Princess Margret hospital ${ }^{1}$ has given many important guidelines about neonatal seizures. Recently N Monod and S Guidasci2 ${ }^{2}$ conducted statistical study of various EEG patterns, factors relating to normality or abnormality and outcome in children. Some types of seizure are associated with relatively high incidence of early death and in survivors, a higher incidence of neurological impairment, development delay and post neonatal epilepsy. Harway B Sarnat and Margret B Sarnat ${ }^{6}$ distinguished three clinical stages of post anoxic encephalopathy and revealed that failure of the EEG to revert to normal was associated with later neurologic impairment or death.

Compared to other methods such as the CT scan or MRI, which provide a snap shot of the brain structure, EEG gives a continuous stream of data that indicates the neurological state of the patient. This makes EEG more suitable for long term monitoring of subjects and for viewing changes in neurological state during the time of recording.

The most common seizure type in neonate is subtle seizures followed by focal clonic and multifocal clonic. ${ }^{3,4}$. Looking at the etiology of neonatal seizures perinatal asphyxia is still the major cause (44.4\%) before 5 days of life. The second major cause is metabolic abnormalities (23.33\%). Hypoxic ischemic encephalopathy depending on severity yields the most abnormal results with $66.66 \%$ background activity suppression for HIE-III ${ }^{5}$. Recently Vasiljevic B et al confirm that a EEG is simple and accurate bedside diagnostic method for assessing extension of hypoxic-ischemic brain damage and early identification of neonates with perinatal HIE who are at high risk of neurodevelopmental impairment ${ }^{7}$.

METHODOLOGY: This study was carried out in department of pediatrics, Kamla Raja Hospital and G. R. Medical College Gwalior. Only term babies having clinical seizures and age less than 28 days were enrolled after taking a written consent from the parents or guardians. Required information of the enrolled cases was recorded in a preformed proforma including the day of onset of seizures and clinical type of seizures. Those babies having more than one type of seizures were recorded in proforma as having mixed type of seizures. Detailed antenatal and natal history was taken.

Possible investigations were done in order to know the cause of the seizures. Electroencephalography (inter ictal) was done in the Department of Neurology Gajra Raja Medical College Gwalior during the course of stay in SCNU (Special care Neonatal Unit) and the pattern was recorded. Second EEG was done at the age of 3 months and again the pattern was recorded in proforma. We used the epidemiological definition of epilepsy which includes occurrence of more than 2 unprovoked seizures episodes more than 24 hours apart.

We used the term ' 1 st EEG' for the EEG done during neonatal period and the term ' $2^{\text {nd }}$ EEG' for the EEG done at the age of 3 months. Following patterns of EEG were recorded and grouped into 3 groups. Each group was having few EEG patterns which ware not repeated in other groups.

GROUP I EEG Pattern -Normal EEG, GROUP II EEG Patterns-Focal/multifocal lateralisation; Positive sharp rolandic waves; Excessive sharp wave activity; Multiple polyspike pattern; Asynchronacy/high voltage delta activity and GROUP III EEG Patterns- Persistent marked voltage suppression; Burst suppression pattern; Isoelectric background pattern

Neurodevelopment assessment of these babies was done at the age of 6 months using ' $C$ Amiel Tison neurodevelopmental assessment tool'. This tool and scoring system was included in our proforma. A score of ' 0 ' was given to the baby who was found to be having normal neurodevelopmental outcome, while score of ' 1 ' and ' 2 ' were given to babies who were having moderate and severe neurodevelopmental delay respectively. All the data were collected and then processed and analysed. Epical 2000 info software was used for calculation of $\chi^{2}$ value, and 
$\mathrm{P}$ value. Fishers exact test for Risk ratio, Odds ratio were applied using 2 X 2 table. Kappa value was calculated for significance of association.

RESULTS: Out of total 60 enrolled cases, 7 cases (11.67\%) were lost during the study. One case died at home by some illness. At the age of six months 52 (86.66\%) cases completed the follow up for neurodevelopmental assessment.

In our study $34(56.66 \%)$ cases were male while $26(43.34 \%)$ were female, making a male female ratio 1.3:1.

Out of total enrolled cases, 46(76.67\%) were delivered vaginally while 14 (23.33\%) were delivered by cesarean section. It indicates that significant proportion of cases was delivered vaginally.

Most (51.5\%) of the seizures had onset within 24 hours (table-1). Clonic seizures were found to be the most common type of seizures $24(40 \%)$ in the present study, followed by subtle 19 (31.67\%), Tonic 12 (20\%), myoclonic 2(3.33\%) and mixed seizures 3(5\%). Those cases that had more than 1 type of seizures were considered as having mixed seizures (table-2). Distribution of etiology of seizures shows Birth asphyxia was the commonest (70\%) cause of seizures followed by hypocalcemic and hypoglycemia (table-3). Distribution of etiology with day of onset of seizures reveals that a total of $66.7 \%$ cases of birth asphyxia had seizures within 24 hours of age, most of the seizure due to metabolic disturbances was found to be of onset between $>24$ hrs. To $<7$ days of age, a total of $66.7 \%$ cases of meningitis had seizures after 7 days of age.

Correlation of EEG pattern with post neonatal epilepsy shows that a total of $12(23.07 \%)$ cases developed epilepsy. Eighty percent of those cases who had burst suppression pattern and $75 \%$ cases of those who had voltage suppression pattern in $1^{\text {st }}$ EEG showed epilepsy. Those cases that had normal pattern $1^{\text {st }}$ EEG, only $4.2 \%$ developed epilepsy (table-4).

Observation of Distribution of neurodevelopmental outcome according to patterns in $1^{\text {st }}$ EEG reveals that a total of 28 cases had abnormal neonatal EEG and out of them 19 were found to be having neurodevelopmental delay. Total 24 cases had normal neonatal EEG and out of them only 3 were found to be having neurodevelopmental delay. $(\mathrm{p}<0.01)$ (table-6).

Distribution of severity of neurodevelopmental outcome with group I, II and III patterns in $1^{\text {st }}$ EEG shows developmental delay in $12.5 \%, 57.9 \%$ and $88.8 \%$ respectively (Table-8)

Distribution of neurodevelopmental outcome according to patterns in $2^{\text {ndEEG (Table-7) }}$ shows that normal pattern in $2^{\text {nd }}$ EEG is significantly $\left(p<0.01\right.$ and $\left.\chi^{2}=68.61\right)$ associated with normal outcome. Multiple polyspike pattern is significantly $\left(\mathrm{p}<0.01, \chi^{2}=12.01\right)$ associated with moderate developmental delay. Burst suppression pattern was seen in 5 cases in $2^{\text {nd }}$ EEG and out of them $4(80 \%)$ had severe delay $\left(p<0.05, \chi^{2}=7.80\right)$. and $1(20 \%)$ had moderate delay showing that this pattern has the poorest prognosis.

Twenty one cases had abnormal EEG at 3 months of age and out of them 19 were having neurodevelopmental delay. Total 31 cases had normal EEG at 3 months of age and out of them only 3 were having neurodevelopmental delay.

Distribution of severity of neurodevelopmental outcome with groups I, II and III patterns in 2nd EEG shows developmental delay in 9.68\%, 84.62\% and 100\% respectively (Table-8)

Comparison between $1^{\text {st }}$ and $2^{\text {nd }}$ EEG for outcome (table-9) clearly shows that the $2^{\text {nd }}$ EEG when compared with $1^{\text {st }} \mathrm{EEG}$, is more predictive of outcome.

DISCUSSION: In the present study $9(15 \%)$ cases were born at home while 51(85\%) were born in hospitals. We enrolled the cases both from inborn unit and out born unit so we had cases of home delivery in the study. 
We found that out of total enrolled cases, 46(76.67\%) were vaginally delivered while 14 $(23.33 \%)$ were delivered by cesarean section. It indicates that significant proportion of cases were delivered vaginally

It was observed that $31(51.67 \%)$ had seizures within 24 hours of life $\left(\mathrm{p}<0.01\right.$ and $\chi^{2}$ $=34.32), 15$ cases (25\%) has seizures between 24 hours -72 hrs. of life. Eight cases (13.33\%) had onset of seizures between 72 hours. -7 days and six (10\%) cases had seizures onset after 7 days of life. This clearly shows that the occurrence of seizures during $<24$ hours is most common and is highly significant. Similarly in a study of neonatal seizures by Ronen Gabriel et al ${ }^{8}$ onset of seizures on first day of life was 36\%, 64\% had onset of seizures within first 48 hours, and $83 \%$ within first week of life.

Clonic seizures in $24(40 \%)$ cases were found most common type of seizures in the present study, followed by subtle 19 (31.67\%), tonic 12 (20\%), myoclonic 2(3.33\%) and mixed seizures $3(5 \%)$. Similarly Ajay Kumar et al ${ }^{9}$ and Tekgul et al ${ }^{10}$ also found the clonic seizure to be the most common type. Brunquell et al ${ }^{11}$ and Lakra Mahaveer et al ${ }^{12}$ showed that subtle seizures are the most common type of neonatal seizures but in the present study clonic seizures were found to be most common, it may be due to the fact that Subtle seizures are difficult to recognize and also difficult to interpret, as they may be normal neonatal activity. This study included only the term babies while the subtle seizures are primarily seen in preterm babies.

Birth asphyxia $42(70 \%)$ was the most common etiology observed in the study followed by hypocalcemia, CNS infection, hypoglycemia and then other causes. Birth asphyxia was significantly associated as a cause of seizures in the study. It was found to be the commonest cause of neonatal seizures in studies by Soni Arun et $\mathrm{al}^{13} 76.9 \%$ of cases and Ronen Gabriel et al ${ }^{8}$ in $40 \%$ of cases. According to most of the studies birth asphyxia is the commonest cause of neonatal seizures followed by metabolic or infectious causes. Intracranial hemorrhage constitutes small percentage of seizures.

In this study two third of the cases having seizures within 24 hours of age were due to birth asphyxia. Most of the seizures due to hypocalcemia and hypoglycemia were found to have onset between $>24$ hours to $<7$ days of age. Majority of the cases of meningitis had onset of convulsion at the age $>7$ days these results were similar to those found by Rose Arthur L et al ${ }^{14}$.

Only one third of the Birth asphyxia cases had normal EEG pattern. Rose and Lombroso ${ }^{15}$ reported abnormalities in HIE in 70\% cases while Mizrahi and Kallaway ${ }^{16}$ reported it in $46.3 \%$ cases. In this study abnormality in EEG in hypocalcemia (28.56\%), hypoglycaemia $34.4 \%$ and meningitis was also similar to those reported by these workers.

In the present study 12 (23.07\%) developed epilepsy. It is mainly seen in those cases that had burst suppression and voltage suppression pattern in neonatal EEG. Similar results were found by Magda et al ${ }^{17}$. This pattern can be considered as a definite indicator of poor prognosis.

C. Amiel Tison method of neurodevelopmental assessment at the age of 6 months revealed that out of 24 cases who had normal pattern $1^{\text {st }}$ EEG $87.50 \%$ were having no delay $12.50 \%$ were having moderate delay. Normal pattern neonatal EEG was significantly associated with no delay. Thirteen cases had multiple poly spike pattern, out of them 4 (30.8\%) were having no delay, $8(61.54 \%)$ had moderated developmental delay $(\mathrm{p}<0.01)$ and one case had severe developmental delay. It shows significant association of multiple poly spike pattern with moderated neurodevelopmental delay. Total 5 cases were having burst suppression pattern and out of them 4(80\%) were having severe neurodevelopmental delay. Similarly Magda et al ${ }^{17}$ found a significant association between abnormal EEG and developmental delay. C Pizzani ${ }^{18}$ also found that EEG patterns like burst suppression, isoelectric patterns and marked voltage suppression are so severely abnormal that they are considered sufficient for the formulation of the prognosis, 
without the need for serial tests. Some authors feel that predictions can be accurately be advanced when the initial EEG shows a burst-suppression pattern or an inactive or isoelectric pattern even if the test is obtained shortly after birth.

These observations show that normal EEG patterns are associated with normal outcome; patterns like positive sharp rolandic waves, excessive sharp wave activity, multiple poly spike pattern and asynchronacy are associated with moderate neurodevelopmental delay while patterns like persistent marked voltage suppression, burst suppression pattern and isoelectric background pattern are associated with severe neurodevelopmental delay. Also when compared, the EEG done at the age of 3 months (2nd EEG) is more predictive of neurodevelopmental delay as compared to the neonatal EEG ( $\left.1{ }^{\text {st }} \mathrm{EEG}\right)$.

This study conclude that the neonatal EEG can predict the neurodevelopmental outcome at the age of 6 months, but in comparison to $1^{\text {st }}$ EEG the EEG done at 3 month's age is more predictive for neurodevelopmental outcome.

Table-1: Distribution of cases according to Day of onset of seizures

\begin{tabular}{|c|c|c|c|c|}
\hline SI.No. & Day of onset of seizures & No. of cases & Percentage & P value / $\chi^{2}$ value \\
\hline 1. & $<24 \mathrm{hrs}$ & 31 & $51.67 \%$ & \multirow{5}{*}{$\mathrm{p}<0.01$ and $\chi^{2}=34.32$} \\
\hline 2. & 24-72 hrs & 15 & $25 \%$ & \\
\hline 3. & 72 hrs -7 days & 08 & $13.33 \%$ & \\
\hline 4. & $>7$ days & 06 & $10 \%$ & \\
\hline & Total & 60 & $100 \%$ & \\
\hline
\end{tabular}

Table-2: Distribution of cases according to type of seizures

\begin{tabular}{|c|c|c|c|}
\hline Sl.No. & Type of seizures & No. of cases & Percentage \\
\hline 1. & Clonic & 24 & $40 \%$ \\
\hline 2. & Subtle & 19 & $31.67 \%$ \\
\hline 3. & Tonic & 12 & $20 \%$ \\
\hline 4. & Myoclonic & 02 & $3.33 \%$ \\
\hline 5. & Mixed & 03 & $5 \%$ \\
\hline \multicolumn{2}{|r|}{ Total } & 60 & $100 \%$ \\
\hline
\end{tabular}

Table-3: Distribution of etiology of seizures

\begin{tabular}{|c|c|c|c|c|}
\hline Sl.No. & Etiology & No. of Cases & Percentage & P value $/ \chi^{2}$ value \\
\hline 1. & Birth Asphyxia & 42 & $70 \%$ & \multirow{6}{*}{$\mathrm{p}<0.01$ and $\chi^{2}=119.38$} \\
\hline 2. & Hypocalcemia & 07 & $11.67 \%$ & \\
\hline 3. & Hypoglycemia & 04 & $6.67 \%$ & \\
\hline 4. & Meningitis & 06 & $10 \%$ & \\
\hline 5. & Other & 01 & $1.66 \%$ & \\
\hline & Total & 60 & $100 \%$ & \\
\hline
\end{tabular}


Table-4: Distribution of EEG pattern with post neonatal epilepsy

\begin{tabular}{|c|l|c|c|}
\hline \multirow{2}{*}{ SI.No. } & \multicolumn{1}{|c|}{ EEG pattern } & Total & Post neonatal epilepsy (\%) \\
\cline { 3 - 4 } & & No. & No. \\
\hline 1. & Normal & 24 & $01(4.2 \%)$ \\
\hline 2. & Focal/ multifocal lateralization & 02 & $00(0 \%)$ \\
\hline 3. & Positive sharp rolandic waves & 01 & $00(0 \%)$ \\
\hline 4. & Excessive sharp waves activity & 01 & $00(0 \%)$ \\
\hline 5. & Periodic low voltage activity & 02 & $01(50 \%)$ \\
\hline 6. & Multiple poly spike pattern & 13 & $03(23.1 \%)$ \\
\hline 7. & Gross asynchronacy/high voltage delta activity & 00 & $00(0 \%)$ \\
\hline 8. & Persistent marked voltage suppression & 04 & $03(75 \%)$ \\
\hline 9. & Burst suppression pattern & 05 & $04(80 \%)$ \\
\hline 10. & Isoelectric background pattern & 00 & $00(0 \%)$ \\
\hline & Total & $\mathbf{5 2}$ & $\mathbf{1 2}(\mathbf{2 3 . 0 1 \% )}$ \\
\hline
\end{tabular}

Table-5: Distribution of pattern of $1{ }^{\text {st }}$ EEG with etiology of seizures

\begin{tabular}{|l|c|c|c|c|c|c|}
\hline \multicolumn{1}{|c|}{ EEG pattern } & $\begin{array}{l}\text { Birth } \\
\text { asphyxia }\end{array}$ & $\begin{array}{l}\text { Hypocalce } \\
\text { mia }\end{array}$ & $\begin{array}{l}\text { Hypoglyce } \\
\text { mia }\end{array}$ & Meningitis & Others & Total \\
\cline { 2 - 7 } & No. (\%) & No. (\%) & No. (\%) & No. (\%) & No. (\%) & No. \\
\hline Normal & $14(33.3 \%)$ & $5(71.4 \%)$ & $03(75 \%)$ & $02(33.3 \%)$ & $00(0 \%)$ & 24 \\
\hline $\begin{array}{l}\text { Focal/ multifocal } \\
\text { lateralization }\end{array}$ & $04(9.5 \%)$ & $1(14.3 \%)$ & $00(0 \%)$ & $00(0 \%)$ & $00(0 \%)$ & 05 \\
\hline $\begin{array}{l}\text { Positive sharp rolandic } \\
\text { waves }\end{array}$ & $02(4.7 \%)$ & $00(0 \%)$ & $00(0 \%)$ & $00(0 \%)$ & $00(0 \%)$ & 02 \\
\hline $\begin{array}{l}\text { Excessive sharp waves } \\
\text { activity }\end{array}$ & $00(0 \%)$ & $00(0 \%)$ & $01(25 \%)$ & $01(16.7 \%)$ & $00(0 \%)$ & 02 \\
\hline $\begin{array}{l}\text { Periodic low voltage } \\
\text { activity }\end{array}$ & $02(4.8 \%)$ & $1(14.3 \%)$ & $00(0 \%)$ & $00(0 \%)$ & $00(0 \%)$ & 03 \\
\hline $\begin{array}{l}\text { Multiple poly spike } \\
\text { pattern }\end{array}$ & $10(28.8 \%)$ & $00(0 \%)$ & $00(0 \%)$ & $02(33.3 \%)$ & $1(100 \%)$ & 13 \\
\hline $\begin{array}{l}\text { Gross asynchronacy/ } \\
\text { high voltage delta activity }\end{array}$ & $01(2.38 \%)$ & $00(0 \%)$ & $00(0 \%)$ & $00(0 \%)$ & $00(0 \%)$ & 01 \\
\hline $\begin{array}{l}\text { Persistent marked } \\
\text { voltage suppression }\end{array}$ & $04(9.5 \%)$ & $00(0 \%)$ & $00(0 \%)$ & $00(0 \%)$ & $00(0 \%)$ & 04 \\
\hline $\begin{array}{l}\text { Burst suppression } \\
\text { pattern }\end{array}$ & $04(9.5 \%)$ & $00(0 \%)$ & $00(0 \%)$ & $01(16.7 \%)$ & $00(0 \%)$ & 05 \\
\hline $\begin{array}{l}\text { Isoelectric background } \\
\text { pattern }\end{array}$ & $01(2.38 \%)$ & $00(0 \%)$ & $00(0 \%)$ & $00(0 \%)$ & $00(0 \%)$ & 01 \\
\hline & $\mathbf{4 2 ( 1 0 0 \% )}$ & $\mathbf{0 7}(\mathbf{1 0 0 \% )}$ & $\mathbf{0 4 ( 1 0 0 \% )}$ & $\mathbf{0 6}(\mathbf{1 0 0 \% )}$ & $\mathbf{0 1 ( 1 0 0 \% )}$ & $\mathbf{6 0}$ \\
\hline
\end{tabular}


Table-6: Distribution of neurodevelopmental outcome according to patterns in $1^{\text {st }}$ EEG

\begin{tabular}{|c|l|c|c|c|c|}
\hline \multirow{2}{*}{$\begin{array}{c}\text { SL. } \\
\text { No. }\end{array}$} & \multicolumn{1}{|c|}{ EEG pattern } & Normal & $\begin{array}{c}\text { Moderate } \\
\text { delay }\end{array}$ & $\begin{array}{c}\text { Severe } \\
\text { delay }\end{array}$ & Total \\
\cline { 3 - 6 } & & No. (\%) & No. (\%) & No. (\%) & No. \\
\hline 1. & Normal & $21(87.5 \%)$ & $03(12.5 \%)$ & $00(0 \%)$ & 24 \\
\hline 2. & Focal/ multifocal lateralization & $02(100 \%)$ & $00(0 \%)$ & $00(0 \%)$ & 02 \\
\hline 3. & Positive sharp rolandic waves & $01(100 \%)$ & $00(0 \%)$ & $00(0 \%)$ & 01 \\
\hline 4. & Excessive sharp waves activity & $01(100 \%)$ & $00(0 \%)$ & $00(0 \%)$ & 01 \\
\hline 5. & Periodic low voltage activity & $00(0 \%)$ & $01(50.0 \%)$ & $01(50.0 \%)$ & 02 \\
\hline 6. & Multiple poly spike pattern & $04(30.8 \%)$ & $08(61.5 \%)$ & $01(7.7 \%)$ & 13 \\
\hline 7. & $\begin{array}{l}\text { Gross asynchronacy/high voltage } \\
\text { delta activity }\end{array}$ & $00(0 \%)$ & $00(0 \%)$ & $00(0 \%)$ & 00 \\
\hline 8. & $\begin{array}{l}\text { Persistent marked voltage } \\
\text { suppression }\end{array}$ & $01(25 \%)$ & $01(25.0 \%)$ & $02(50.0 \%)$ & 04 \\
\hline 9. & Burst suppression pattern & $00(0 \%)$ & $01(20.0 \%)$ & $04(80.0 \%)$ & 05 \\
\hline 10. & Isoelectric background pattern & $00(0 \%)$ & $00(0 \%)$ & $00(0 \%)$ & 00 \\
\hline & Total & $\mathbf{3 0 ( 5 7 . 7 \% )}$ & $\mathbf{1 4 ( 2 6 . 9 2 \% )}$ & $\mathbf{0 8 ( 1 5 . 3 8 \% )}$ & $\mathbf{5 2}$ \\
\hline
\end{tabular}

Table-7: Distribution of neurodevelopmental outcome according to patterns in $2^{\text {nd }}$ EEG

\begin{tabular}{|c|l|c|c|c|c|}
\hline \multirow{2}{*}{$\begin{array}{c}\text { SL. } \\
\text { No. }\end{array}$} & \multicolumn{1}{|c|}{ EEG pattern } & Normal & $\begin{array}{c}\text { Moderate } \\
\text { delay }\end{array}$ & $\begin{array}{c}\text { Severe } \\
\text { delay }\end{array}$ & Total \\
\cline { 2 - 5 } & & No. (\%) & No. (\%) & No. (\%) & No. \\
\hline 1. & Normal & $28(90.32 \%)$ & $3(9.68 \%)$ & $00(0 \%)$ & 31 \\
\hline 2. & Focal/ multifocal lateralization & $01(100 \%)$ & $00(0 \%)$ & $00(0 \%)$ & 01 \\
\hline 3. & Positive sharp rolandic waves & $00(0 \%)$ & $00(0 \%)$ & $00(0 \%)$ & 00 \\
\hline 4. & Excessive sharp waves activity & $00(0 \%)$ & $01(100 \%)$ & $00(0 \%)$ & 01 \\
\hline 5. & Periodic low voltage activity & $00(0 \%)$ & $01(50.0 \%)$ & $01(50.0 \%)$ & 02 \\
\hline 6. & Multiple poly spike pattern & $01(11.1 \%)$ & $07(77.8 \%)$ & $01(11.1 \%)$ & 09 \\
\hline 7. & $\begin{array}{l}\text { Gross asynchronacy/high voltage } \\
\text { delta activity }\end{array}$ & $00(0 \%)$ & $00(0 \%)$ & $00(0 \%)$ & 00 \\
\hline 8. & $\begin{array}{l}\text { Persistent marked voltage } \\
\text { suppression }\end{array}$ & $00(0 \%)$ & $01(33.3 \%)$ & $02(66.7 \%)$ & 03 \\
\hline 9. & Burst suppression pattern & $00(0 \%)$ & $01(20.0 \%)$ & $04(80.0 \%)$ & 05 \\
\hline 10. & Isoelectric background pattern & $00(0 \%)$ & $00(0 \%)$ & $00(0 \%)$ & 00 \\
\hline \multicolumn{2}{|c|}{ Total } & $\mathbf{3 0 ( 5 7 . 7 \% )}$ & $\mathbf{1 4 ( 2 6 . 9 \% )}$ & $\mathbf{0 8 ( 1 5 . 3 8 \% )}$ & $\mathbf{5 2}$ \\
\hline
\end{tabular}


Table-8: Distribution of severity of neurodevelopmental outcome with group I, II and III patterns in 1st and 2nd EEG

\begin{tabular}{|c|c|c|c|c|c|c|c|}
\hline \multirow{2}{*}{$\begin{array}{c}\text { S. } \\
\text { No } \\
\text {. }\end{array}$} & \multirow{2}{*}{$\begin{array}{l}\text { Group(number } \\
\text { of cases in } \\
\text { each group) }\end{array}$} & \multicolumn{3}{|c|}{$1^{\text {st }}$ EEG } & \multicolumn{3}{|c|}{$2^{\text {nd }}$ EEG } \\
\hline & & $\begin{array}{l}\text { Normal } \\
\text { outcome }\end{array}$ & $\begin{array}{c}\text { Moderate } \\
\text { delay }\end{array}$ & $\begin{array}{c}\text { Severe } \\
\text { delay }\end{array}$ & $\begin{array}{l}\text { Normal } \\
\text { outcome }\end{array}$ & $\begin{array}{c}\text { Moderate } \\
\text { delay }\end{array}$ & $\begin{array}{c}\text { Severe } \\
\text { delay }\end{array}$ \\
\hline 1 & $\begin{array}{l}\text { Group I } \\
\text { pattern }\end{array}$ & $21(87.50 \%)$ & $3(12.50 \%)$ & $0(0 \%)$ & $28(90.32 \%)$ & $3(9.68 \%)$ & $0(0 \%)$ \\
\hline 2 & $\begin{array}{c}\text { Group II } \\
\text { pattern }\end{array}$ & $8(42.10 \%)$ & $9(47.37 \%)$ & $2(10.53 \%)$ & $2(15.38 \%)$ & $9(69.24 \%)$ & $2(15.38 \%)$ \\
\hline 3 & $\begin{array}{l}\text { Group III } \\
\text { pattern }\end{array}$ & $1(11.11 \%)$ & $2(22.22 \%)$ & $6(66.67 \%)$ & $0(0 \%)$ & $2(25 \%)$ & $6(75 \%)$ \\
\hline & Total & 30 & 14 & 08 & 30 & 14 & 08 \\
\hline
\end{tabular}

Table-9: Statistical analysis of $1^{\text {st }}$ and $2^{\text {nd }}$ EEG for developmental delay

\begin{tabular}{|l|c|c|}
\hline & Abnormal 1st EEG & Abnormal 2nd EEG \\
\hline P value for Dev. delay & $<0.01$ & $<0.01$ \\
\hline Relative risk & $5.428(95 \mathrm{CI}-0.83-16.13)$ & $9.35(95 \mathrm{CI} 3.16-27.65)$ \\
\hline Kappa value 'k' & 0.544 & 0.80 \\
\hline Sensitivity & $0.86(86.4)$ & $0.86(86.4)$ \\
\hline Specificity & $0.7(70 \%)$ & $0.93(93.3 \%)$ \\
\hline Positive predictive value & $0.68(67.8 \%)$ & $0.90(90.5 \%)$ \\
\hline Negative predictive value & $0.86(87.5 \%)$ & $0.90(90.3 \%)$ \\
\hline
\end{tabular}

\section{REFERENCES:}

1. Clinical guidelines of neonatal neurology, King Edward Memorial/ Princes Margret Hospital. Revised July 2006 Perth Western Australia.

2. N Monod, N Pajot and S Guidasci. Electroencephalography \& clinical neurophysiology. Volume 32 issue 5 may 1972; 529-544.

3. Brunquell Philip J et al. Prediction of outcome based on clinical seizures type in newborn infants. The Journal of Pediatrics, June 2002; 140(6): 707-712.

4. Lakra Mahaveer, Vilhekar KY, Chaturvedi Pushpa. Clinico-biochemical profile of neonatal seizures in a rural medical college. In: Fernandez A, Dadhich JP, Saluja S, Editors, Abstracts, XXIII Annual Convention of National Neonatology Forum, Dec. 18-21, 2003; Hyderabad. 2003: 121-122.

5. Kumar A, Gupta A, Talukdar B. Clinico-etiological and EEG profile of neonatal seizures. Indian J Pediatr. Jan 2007; 74(1):33-7.

6. Harwey B Sarnat, Margret S Sarnat. Arch neurol 1976:33(10) 696-705.

7. Vasiljevic B, Maglajlic-Djukic S, Gojnic M. The prognostic value of amplitude-integrated electroencephalography in neonates with hypoxic-ischemic encephalopathy. Vojnosanit Pregl.2012 Jun; 69(6):492-9. 
8. Ronen Gabriel M, Penny Sharon RN, Andrews S Wayne. The epidemiology of clinical neonatal seizures in Newfound Land: A population-based study. The Journal of Pediatrics, Jan 1999; 134(1): 71-75.)

9. Kumar A, Gupta A, Talukdar B. Clinico-etiological and EEG profile of neonatal seizures. Indian J Pediatr. Jan 2007; 74(1):33-7.

10. Tekgul et al. The current etiologic profile and neurodevelopmental outcome of seizures in term neonates. Pediatrics Volume 117, Number 4, April 2006, P. 1270.)

11. Brunquell Philip J et al. Prediction of outcome based on clinical seizures type in newborn infants. The Journal of Pediatrics, June 2002; 140(6): 707-712.

12. Lakra Mahaveer, Vilhekar KY, Chaturvedi Pushpa. Clinico-biochemical profile of neonatal seizures in a rural medical college. In: Fernandez A, Dadhich JP, Saluja S, Editors, Abstracts, XXIII Annual Convention of National Neonatology Forum, Dec. 18-21, 2003; Hyderabad. 2003: 121-122.

13. Soni Arun et al. Clinical profile of seizures in neonatal intensive care unit. In: Fernandez A, Dadhich JP, Saluja S, Editors, Abstracts, XXIII Annual Convention of National Neonatology Forum, Dec. 18-21, 2003; Hyderabad. 2003: 109-111.

14. Rose Arthur MB, Lombroso Cesare T. Neonatal seizures states. A study of clinical, pathological and electroencephalographic features in 137 full-term babies with a longterm follow up. Pediatrics, March 1970; 45(3): 404-425.

15. Rose Arthur MB, Lombroso Cesare T. Neonatal seizures states. A study of clinical, pathological and electroencephalographic features in 137 full-term babies with a longterm follow up. Pediatrics, March 1970; 45(3): 404-425.

16. Mizrahi M, Kellaway Peter. Characterization and classification of neonatal seizures. Neurology, 1987; 37: 1837-44.

17. Magda et al Arq. Neur Psiquiatr. vol.66 no.2a São Paulo 2008 June 168-174

18. C. Pezzani, M.F. Radvanyi-Bouvet, J.P. Relier and M. Monod, Neonatal electroencephalography during the first twenty-four hr of life in full-term newborn infants, Neuropediatrics 17 (1986), 11-18.

\section{AUTHORS:}

1. Yogendra S. Verma

2. Rajdhar Dutt

3. Neelam Rajput

4. Rajesh Patil

\section{PARTICULARS OF CONTRIBUTORS:}

1. Assistant Professor, Department of Pediatrics, G.R. Medical College, Gwalior.

2. Associate Professor, Department of Pediatrics, G.R. Medical College, Gwalior.

3. Assistant Professor, Department of Obstetrics and Gynaecology, G.R. Medical College, Gwalior.

4. Post Graduate Resident doctor, Department of Pediatrics, G.R. Medical College, Gwalior.

\section{NAME ADRRESS EMAIL ID OF THE CORRESPONDING AUTHOR:}

Dr. Yogendra S. Verma, Assistant Professor, Department of Pediatrics, Kamla Raja Hospital and G.R. Medical College, Gwalior (M.P.) - 474001.

Email-drvermayogendra@yahoo.co.in

Date of Submission: 14/07/2013. Date of Peer Review: 14/07/2013. Date of Acceptance: 16/07/2013. Date of Publishing: 19/07/2013 